\title{
Lithium-Ion Capacitor - Advanced Technology for Rechargeable Energy Storage Systems
}

\author{
N. Omar ${ }^{1}$, J. Ronsmans ${ }^{2}$, Yousef Firozu ${ }^{1}$, Mohamed Abdel Monem ${ }^{1}$, A. Samba, H. Gualous ${ }^{3}$, \\ O. Hegazy ${ }^{1}$, J. Smekens, Th. Coosemans ${ }^{1}$, P. Van den Bossche ${ }^{1}$, J. Van Mierlo ${ }^{1}$ \\ Vrije Universiteit Brussel, Pleinlaan 2, Brussels, 1050, Belgium, \\ JSR Micro N.V., Technologielaan 8, Leuven, 3001, Belgium \\ 3 Université de Caen Basse Normandie, Cherbourg-Octeville, France \\ Correspondingauthor: noshomar@vub.ac.be
}

\begin{abstract}
This paper presents the electrical and thermal behaviour of an advanced lithium-ion capacitor (LIC) based rechargeable energy storage systems. In the proposed study, an extended statistical analysis has been performed to evaluate the main electrical parameters such as resistance, power, capacitance, rate capabilities, variation between cells and thermal parameters. Based on the performed analysis, an electrical model has been developed for dimensioning and evaluation of various applications based on lithium-ion capacitor technology.
\end{abstract}

Keywords: Lithium-Ion Capacitor, EDLC, Lithium-Ion Battery, HEV, BEV

\section{Introduction}

Since the beginning of the automobile era, the internal combustion engine (ICE) has been used for vehicular propulsions. In addition, motor vehicles powered by the ICE are significant contributors to air pollutants and greenhouse gases linked to the global climate change $[1,2]$. As the global economy begins to strain under the pressure of rising petroleum prices and environmental concerns, research has spurred the development of various types of the clean energy transportation systems such as Hybrid Electric Vehicles (HEVs), Battery Electric Vehicles (BEVs) and Plug-in Hybrid Electric Vehicles (PHEVs) [3,4]. However, the establishment of the energy storage technology, which can support the output power during acceleration, the efficient use of the regenerative energy and considerable life cycle, are the critical aspects. Furthermore, there is no current battery technology can meet these often concurrent objectives [4-12].

A possible solution for enhancing the present battery performances is the hybridization of batteries with electrical double-layer capacitors (EDLCs) [13-14]. However, such hybrid architecture needs expensive and high efficient DCDC converters. This makes this combination less attractive in mobile applications where cost, weight and volume can be considered as main barriers [14].

In order to overcome these obstacles, in the last decade, several types of advanced rechargeable energy storage systems have been developed by many companies and research centers (called lithium-ion capacitors or hybrid capacitors) [15-20]. In [21-24], the general performances of these technologies have been investigated. In this study, they observed that an energy density of $14 \mathrm{Wh} / \mathrm{kg}$ and over $10000 \mathrm{~W} / \mathrm{kg}$ could be achieved. In [2528], the suitability of the proposed technology has been analyzed. From these works, it can be seen that lithium-ion capacitors can act as a main power or energy source without any reduction of the system capabilities.

Furthermore, the LIC seems in certain sense more attractive than EDLCs due to their higher operating 
conditions (such as voltage $3.8 \mathrm{~V}$ max. compared to $2.7 \mathrm{~V}$ for EDLCs). This means that the needed cells that are connected in series will be lower, and the complexity of the entire system will be reduced.

\section{Working mechanism lithium- ion capacitor}

The Lithium-Ion Capacitor is a rechargeable energy storage system, which belongs to the class of hybrid capacitors or asymmetric capacitors. It can be classified between lithium-ion batteries and electrical-double layer capacitor (EDLC) The positive electrode uses porous activated carbon as in conventional EDLCs. The electrode has been prepared by carbonized of precursors. The specific capacitance of the electrode is about $100 \mathrm{~F} / \mathrm{g}$, which is assumed based on $1000 \mathrm{~m}^{2} / \mathrm{g}$ for the surface area of the electrode and $0.1 \mathrm{~F} / \mathrm{m}^{2}$ for the double-layer [14]. The negative electrode also uses carbon material with significant Li-ion pre-doped with lithium-ion on its negative electrode (see Figure 1) [1,6-10]. The used electrolyte is an organic based carbonate mixture. The key technology is the pre-doping of the Li to the anode carbon for enhancing the energy density. The Li foil is set close to the assembled electrodes, which are supported by porous current collectors and is connected with porous current collector of the anode. After impregnation of electrolyte, $\mathrm{Li}$ pre-doping proceeds by dissolving $\mathrm{Li}$ into the electrolyte and moving into anode to low the potential of anode carbon. The anode potential is lowered by charging process of the LIC. The potential of the negative electrode can be kept low during discharge of the cell since the capacity of anode is significantly larger than that of cathode [11]. Figure 1 shows the elementary structure of lithium-ion, EDLC and Li-ion capacitor structure.

It can be seen that the negative LIC electrode is formed by Li doped carbon. The LIC equivalent capacitance is formed by the positive electrode capacitance $\mathrm{C}^{+}$in series with the negative one $\mathrm{C}^{-}$. The equivalent capacitor can be expressed as following:

$\frac{1}{C_{\text {cell }}}=\frac{1}{C^{-}}+\frac{1}{C^{+}}$

Since $\mathrm{C}^{-}$is much higher than $\mathrm{C}^{+}$, the capacitance of the LIC cell $\mathrm{C}_{\text {cell }}$ is nearly equal to the capacitance of the activated carbon-electrolyte $\mathrm{C}^{+}$. Here, it should be noted that occur of thermal runaway is limited since the cathode material is composed of activated carbon as in conventional EDLCs.

In this paper, the prismatic lithium-ion capacitor cells $3300 \mathrm{~F}$ fabricated from JM Energy have been investigated. The main characteristics of this LIC type are summarized below:

- Nominal capacitance: 3300F,

- Weight: $350 \mathrm{~g}$,

- Maximum voltage: $3.8 \mathrm{~V}$,

- Minimum voltage: $2.2 \mathrm{~V}$,

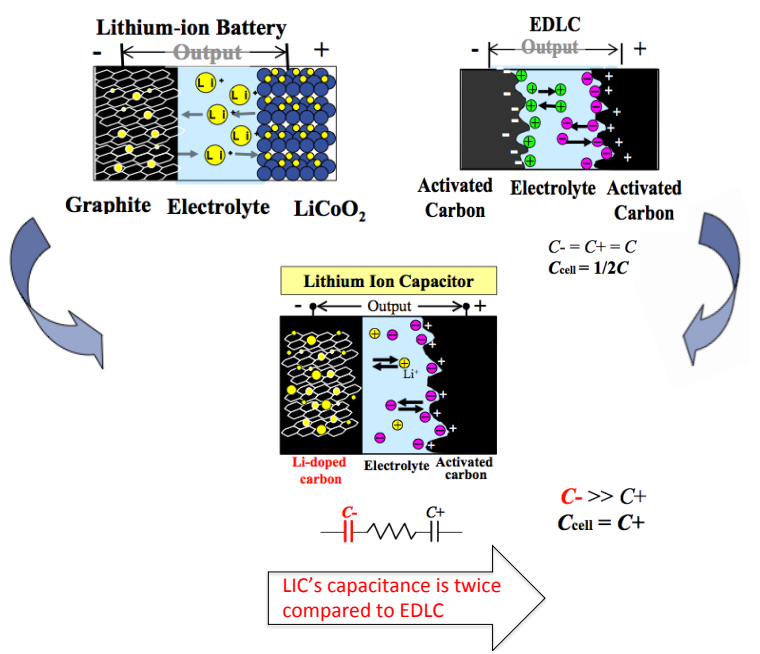

Figure 1: Comparison working mechanisms of EDLCs, lithium-ion batteries and LIC

\section{Applications \& Requirements}

In the last decade, EDLCs have been implemented in many applications where the peak power is needed. However, the energy content of the EDLCs is not enough whereby several parallel stacks are required. From this context, the use of lithium-ion capacitors could be an interesting solution in vehicular applications where still high peak powers with higher energy content than EDLCs are desired. Furthermore, the selection of the investigated prismatic LIC has the advantages in terms of compact integration in a pack. In addition, the prismatic shape offers significant space advantage, which can be considered of high importance in mobile applications such as buses, trams and metros. 


\begin{tabular}{|l|c|c|c|c|}
\hline Application & Voltage [V] & Power [W] & Cycle life & Duration \\
\hline Bus & $700-800$ & $150 \mathrm{k}$ & 1000.000 cycles & $10 \mathrm{~s}$ \\
\hline Metros & $800-900$ & $1-2 \mathrm{M}$ & $200.000-400.000$ cycles $(1$ year $)$ & $10-20 \mathrm{~s}$ \\
\hline Trams & 700 & $300 \mathrm{k}-400 \mathrm{k}$ & $?$ & $10-20 \mathrm{~s}$ \\
\hline Load leveling & 400 & $200 \mathrm{k}-1 \mathrm{G}$ & $2500(10$ years $)$ & $50-300 \mathrm{~min}$ \\
\hline Back-up power & 400 & $1 \mathrm{k}-1 \mathrm{M}$ & $100(10$ years $)$ & $15 \mathrm{~min}$ \\
\hline Cranes & 800 & $350 \mathrm{k}$ & 1000.000 cycles & $10 \mathrm{~s}$ \\
\hline
\end{tabular}

Table 1: Specifications of some applications

\section{Test methodology}

In this study, a methodology as presented in Figure 2 has been used for investigating the performances of the proposed LIC cells. As one can observe the methodology consists of electrical, thermal and electrochemical impedance spectroscopy (EIS) tests.

The proposed methodology will assist us to have the required insight of the LIC performances in terms of energy, capacity, power, thermal and EIS performances at different working conditions such as current, ambient temperature and state of charge (SoC).

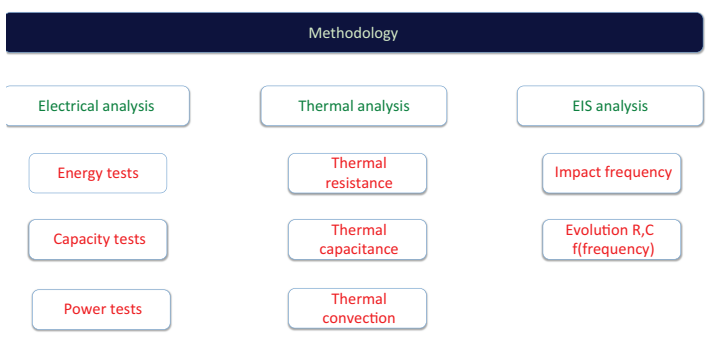

Figure 2: Test methodology

\section{Results}

\subsection{Energy test}

In Figure 3, the energy density evolution of the LIC is demonstrated. The energy test has been conducted at $10 \mathrm{~A}$ charging until maximum voltage $(3.8 \mathrm{~V})$ following by constant voltage until the current was reduced to $0.01 \mathrm{~A}$. After a rest period of 15 minutes the cells have been discharged at different current rates till $2.2 \mathrm{~V}$, which is the minimum voltage. Prior starting the tests, the cells have been placed in a climate chamber at the desired temperature for a period of 3 hours.

As one can observe the energy density of the LIC at $10 \mathrm{~A}$ discharge is between $12.1 \mathrm{Wh} / \mathrm{kg}$ and 11.4 $\mathrm{Wh} / \mathrm{kg}$ at ambient temperatures between $60^{\circ} \mathrm{C}$ and $-10^{\circ} \mathrm{C}$, respectively. Then, the energy density decreases slightly as a function of the applied current. At 200A, the energy density is between $10.2 \mathrm{Wh} / \mathrm{kg}$ and $6.6 \mathrm{Wh} / \mathrm{kg}$.

In [24], the authors documented that the increase of the energy density of the EDLCs is less dependent on the above-mentioned parameters. The reason is attributed to the pseudo-capacitance reactions that occur in the LIC. In [29], the authors reported that the decrease of the energy in the LIC at low temperatures is due to the increase of the electrolyte resistance. Here one can conclude that the role of the thermal management is vital for LIC for keeping the cells or the system in the appropriate operating window, where high performances can be assured.

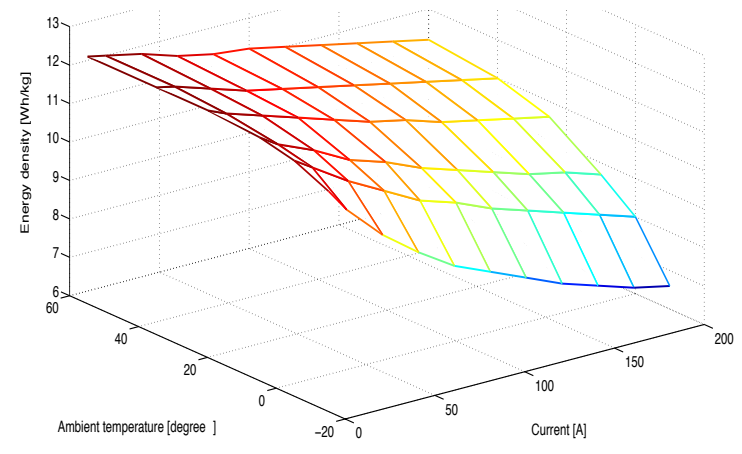

Figure 3: Energy density evolution versus current rate and ambient temperature

\subsection{Capacity test}

In load levelling and back-up power applications, the LIC should to be able to supply the required capacity or power during a specific duration. According to the specifications as can be found in Table 1, the operation duration could be between 15 and 300 minutes.

Therefore, in Figure 4, the capacity evolution has been obtained from the previous test at different current rates and ambient temperatures. As we can see, the capacity decreases more pronounced compared to EDLC as function of current rates and ambient temperature. The obtained evolution 
is similar to the high power lithium-ion batteries such as lithium titanate oxide based [8].

This evolution predicts that the Peukert number for the LIC is higher than 1 as can be seen in Figure 5. In Figure 5 one can see that the Peukert number changes between 1.02 and 1.11 in the temperature range $60^{\circ} \mathrm{C}$ and $-10^{\circ} \mathrm{C}$.

Peukert phenomenon is an empirical relationship, which describes the rate capabilities of the cell at different current rates. The general equation of the Peukert relationship is presented by equation (2):

$C_{d i s}=T \cdot I^{k}$

where $\mathrm{C}_{\mathrm{p}}$ is the discharge capacity in Ah, while $\mathrm{T}$ is the time in second and I represents the discharge current, respectively. $\mathrm{k}$ is the Peukert constant, and equals to one for an ideal rechargeable energy storage systems where the capacity is almost equal independent of the employed current.

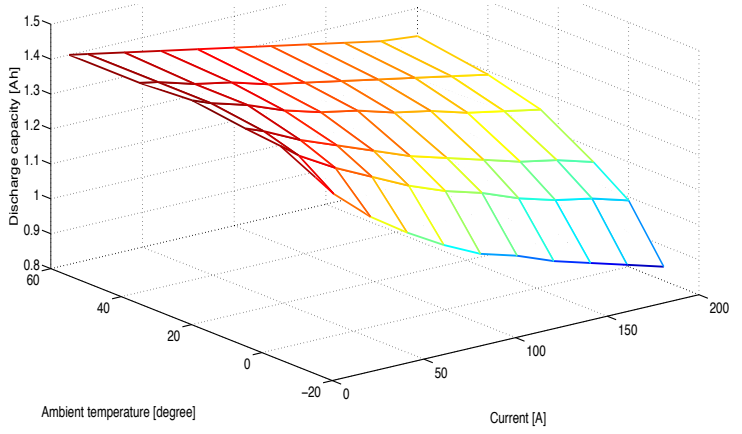

Figure 4: Evolution of the discharge capacity as function of current rate at different ambient temperatures

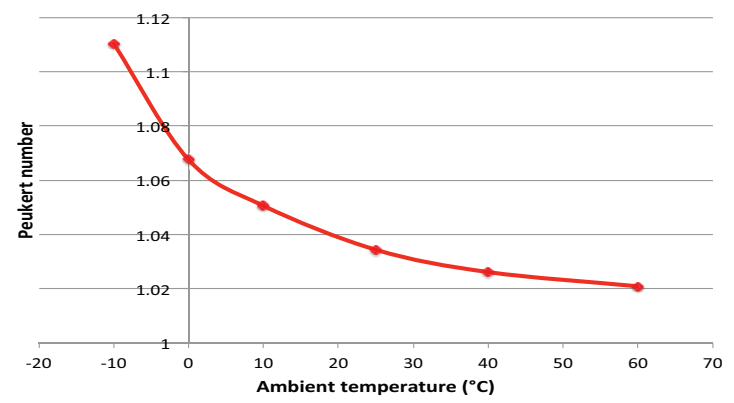

Figure 5: Evolution of Peukert number versus ambient temperature

\subsection{Power capabilities}

Besides energy, power requirements can be considered as a key criterion in the application of LIC. In most applications, the LIC should to have high power capabilities during discharge and charge as well.

Therefore, in this paper, an extended analysis has been performed to evaluate the power performances of the proposed LIC at different $\mathrm{SoC}$ (from $0 \%$ to $100 \%$ with steps of $5 \%$ ), at current rates (20A to $200 \mathrm{~A}$ with steps of $20 \mathrm{~A}$ ) and at the same working temperatures as in sections 5.1 and 5.2.

The power capabilities have been investigated based on 1 second pulses during charging and discharging.

In Figure 6, the experimental results of the power density versus state of charge during one-second pulse at different working temperatures are illustrated. The power density has been calculated based on the equation (3).

$P_{\text {density }}=\frac{U_{\text {rated }}^{2}}{4 \cdot m \cdot R}$

Where,

$\mathrm{P}_{\text {density: }}$ power density $[\mathrm{W} / \mathrm{kg}]$,

$\mathrm{U}_{\text {rated }}$ : the voltage at specific SoC $[\mathrm{V}]$,

$\mathrm{R}$ : internal resistance of LIC during the pulse $[\Omega]$, $\mathrm{m}$ : mass of the LIC cell $[\mathrm{kg}]$,

As we can observe the power density of the LIC is strongly depending on the working temperature. As one can notice that the power density $\left(\right.$ at $60^{\circ} \mathrm{C}$, $100 \% \mathrm{SoC}$ ) is $9000 \mathrm{~W} / \mathrm{kg}$ against $3170 \mathrm{~W} / \mathrm{kg}$ (at $10^{\circ} \mathrm{C}$ ). The decrease of the power at lower temperatures is attributed to the increase of the electrolyte resistance [24]. From Figure 6, we can conclude that LIC cells are able to supply peak powers at lower SoC levels as well. However, the peak powers at higher SoC levels are significantly higher.

Here it should be noted that the applied current was only limited to 200A. However, from Figure 7 , we can observe that the voltage drop at high SoC levels is not big, which means that higher current rates can be applied. Since the resistance of the LIC decreases as a function of current, the power density will increase significantly at higher current rates.

Here it should be noted that the LIC cells need a thermal management to keep the cells in the appropriate operating conditions where high performances can be guaranteed. 


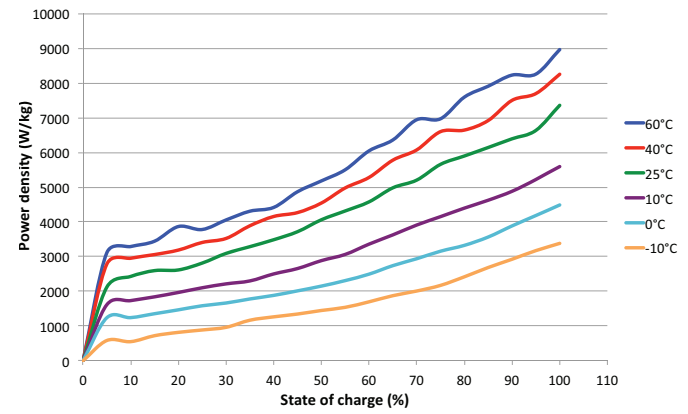

Figure 6: Discharge power density versus state of charge

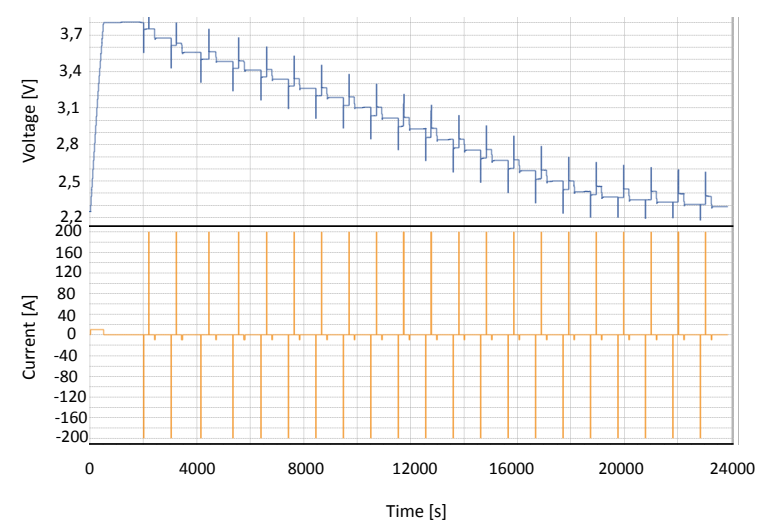

Figure 7: Representation of the voltage and current versus time during $\mathrm{HPPC}$ tests at $25^{\circ} \mathrm{C}$ and $200 \mathrm{~A}$

\subsection{Impact frequency}

In the field of energy storage testing, the electrochemical impedance spectroscopy can be considered as of high importance. Based on the evolution of the impedance as a function of frequency, some additional information can be obtained, which is only possible by using the battery tester.

In Figure 8, the evolution of the EIS measurements at different voltage levels is illustrated. As we can observe, in Figure 8, at $3.8 \mathrm{~V}$ the bulk resistance is about $0.74 \mathrm{~m} \Omega$.

In [23], the authors indicated that the series resistance of LICs consists of the bulk resistance, the charge transfer resistance and the diffusion resistance. The bulk resistance $R_{b}$ represents the intersection with the real axis. The charge transfer resistance $R_{e}$ is the half circle, while the diffusion resistance starts when the resistance $R_{e}$ ends. However, from Figure 8, the charge transfer resistance is difficult to observe.

It is clear that there is a shift of the bulk resistance over the real axis when the cell voltage changes. Generally, one can conclude that the resistance $\mathrm{R}_{\mathrm{e}}$ increases when the voltage decreases.
Another phenomenon that can be noticed at low frequencies is the shift of the spectra as function of the rated voltage.

This indicates that at low frequencies the LIC behaves as a capacitive cell. This observation also can be approved by Figure 8, where the phase at $10 \mathrm{mHz}$ is about $-80^{\circ}$. Here it should be noted that the differences in phase at different voltage levels are small. However, the variations at $10 \mathrm{kHz}$ are high.

Furthermore, in Figure 10, one can notice that the appropriate frequency range is between $0.1 \mathrm{~Hz}$ and $1 \mathrm{kHz}$. This is due to the smaller impedance.

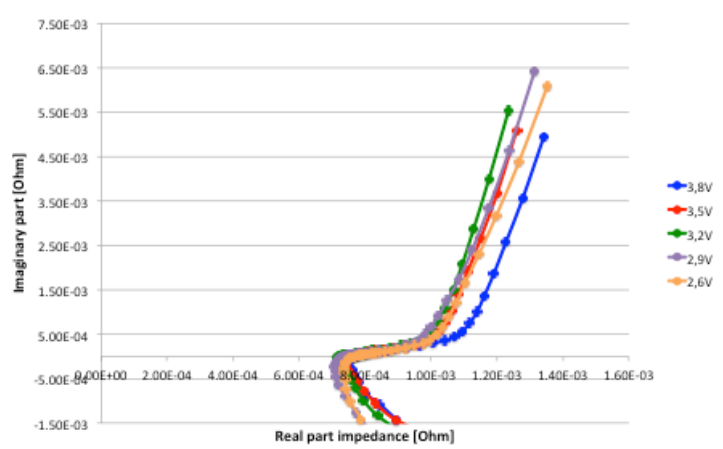

Figure 8: Nyguist plot at different voltage levels

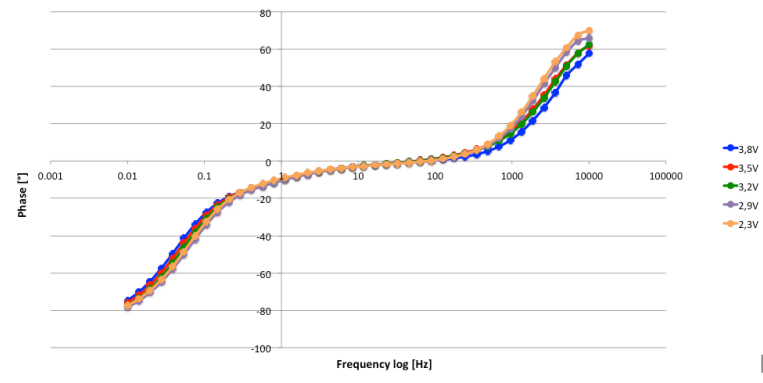

Figure 9: Phase evolution versus frequency at different voltage levels

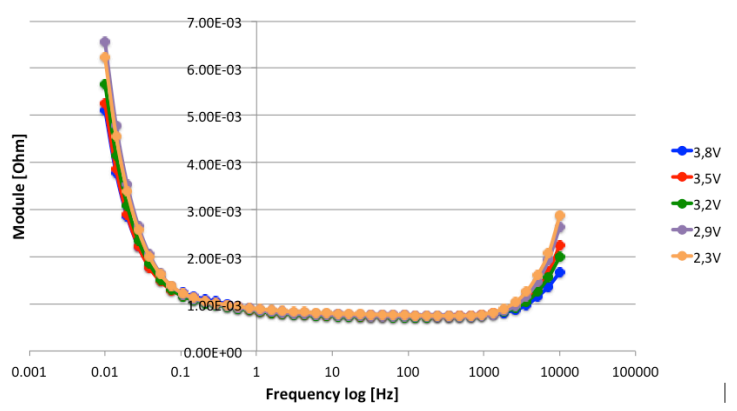

Figure 10: Module evolution versus frequency at different voltage levels

Since the capacitance of the LIC is depending on the voltage, there is a need to have a clear view of the capacitance performances as a function of voltage level. In Figure 11, the capacitance of the 
LIC at $25^{\circ} \mathrm{C}$ and different voltage levels is demonstrated. As one can notice, the capacitance is clearly varying as a function of voltage in the frequency range $10 \mathrm{mHz}$ and $1 \mathrm{~Hz}$. Here it should be underlined that the capacitance at $2.6 \mathrm{~V}$ is higher than at $2.9 \mathrm{~V}$. The reason for this result can be explained by the higher increase of the imaginary part of the impedance at $2.9 \mathrm{~V}$ against at $2.6 \mathrm{~V}$ as can be seen in Figure 8 .

The capacitance of the LIC has been calculated based on the equation (4):

$C=\frac{-1}{2 * \pi * f * Z(f)}$

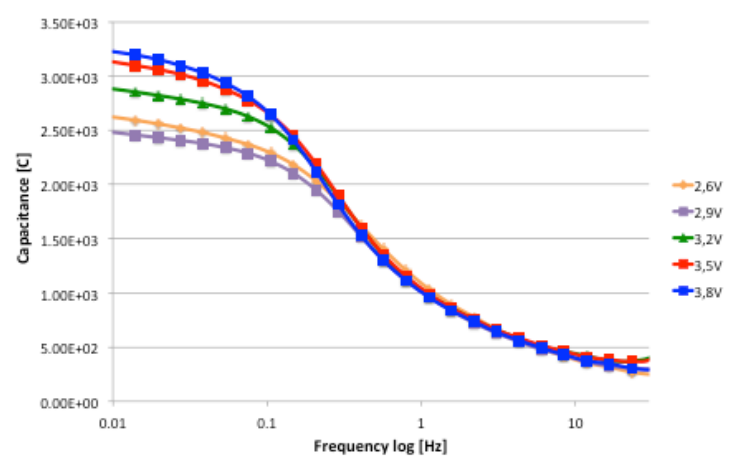

Figure 11: Capacitance versus frequency at different voltage level

\subsection{Thermal behaviour}

Prediction of thermal behaviour of energy storage systems can be considered nowadays of high importance in the scientific community. The temperature of the cell in real applications should be monitored in order to avoid critical situation like thermal runaway. Then, the performances of cells are strongly temperature dependent, which indicates that the need of a thermal management is high.

Therefore, accurate thermal models could be interesting tool to examine the thermal behaviour of LIC cells in advance.

In this paper, a test profile as illustrated in Figure 12 has been used. The profile exists of charge and discharge pulses at $100 \mathrm{~A}$. The pulse durations are $3 \mathrm{~s}$ with $1 \mathrm{~s}$ rest time between charge and discharge. The proposed test has been carried out at $25^{\circ} \mathrm{C}$. From this test, one can observe that the temperature increases until the temperature is stabilized.

Based on such evolution, the thermal parameters such as thermal resistance $\mathrm{R}_{\text {th }}$, thermal convection $\mathrm{R}_{\text {con }}$, thermal capacitance $\mathrm{C}_{\text {th }}$ and thermal time constant $\tau_{\text {th }}$ can be determined.
The thermal convection, which describes the heat exchange between the cell surface and the environment, has been calculated based on the equation (5):

$R_{\text {con }}=\frac{T_{a}-T_{\text {surface }}}{R \cdot I^{2}}$

where

$\mathrm{R}_{\text {con }}$ : the thermal convection $\left[{ }^{\circ} \mathrm{C} / \mathrm{W}\right]$,

$\mathrm{T}_{\mathrm{a}}$ : the ambient temperature $\left[{ }^{\circ} \mathrm{C}\right]$,

$\mathrm{T}_{\mathrm{S}}$ : the surface temperature of the cell $\left[{ }^{\circ} \mathrm{C}\right]$,

$\mathrm{R}$ : the internal resistance of the cell $[\Omega]$,

I: the current through the cell [A],

The calculated thermal convection is $1.42{ }^{\circ} \mathrm{C} / \mathrm{W}$.

Since the evolution of the temperature is a first order, the thermal time constant is $66 \%$ of the value when the temperature stabilizes. In this case, the time constant is $1300 \mathrm{~s}$.

In literature, it is generally known that the thermal resistance of such technology is about $3-3.2^{\circ} \mathrm{C} / \mathrm{W}$ [30].

Based on those parameters, the thermal capacitance can be determined as follows:

$\tau_{t h}=C_{t h} \cdot\left(R_{t h}+R_{c o n}\right)$

According to the calculated parameters, the thermal capacitance is $294 \mathrm{~J} /{ }^{\circ} \mathrm{C}$.

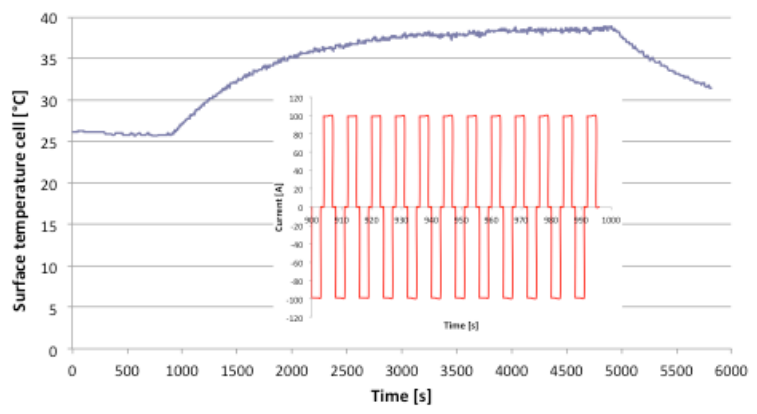

Figure 12: Temperature evolution during cycling the LIC cell at $25^{\circ} \mathrm{C} \& 100 \mathrm{~A}$

\subsection{Voltage characteristics}

Since lithium-ion capacitors are emerging rechargeable energy storage technology, there is up to now no clear answer if they belong the EDLCs or lithium-ion technology. In order to answer on this question, the voltage response during one second pulse at $100 \mathrm{~A}$ discharge and at 
$25^{\circ} \mathrm{C}$ as demonstrated in Figure 13 has been investigated in depth.

In the case of EDLCs, the voltage response during a pulse reveals an immediate voltage drop, which stands for the equivalent series resistance (ESR) as indicated in the standard IEC 62576 [31]. Then, the voltage decreases linearly. However, Figure 13 reveals that the voltage shows an immediate voltage drop, which indicates the ohmic resistance of the LIC. Then, the voltage decreases exponentially till the end of the pulse, which represents the polarization behaviour. As indicated in [8], this evolution is comparable to lithium-ion batteries.

From this point of view, one can conclude that LIC belong the lithium-ion group, but with very high power capabilities. Thus, the standard IEC 62660-1 also can be applied on LICs [32].

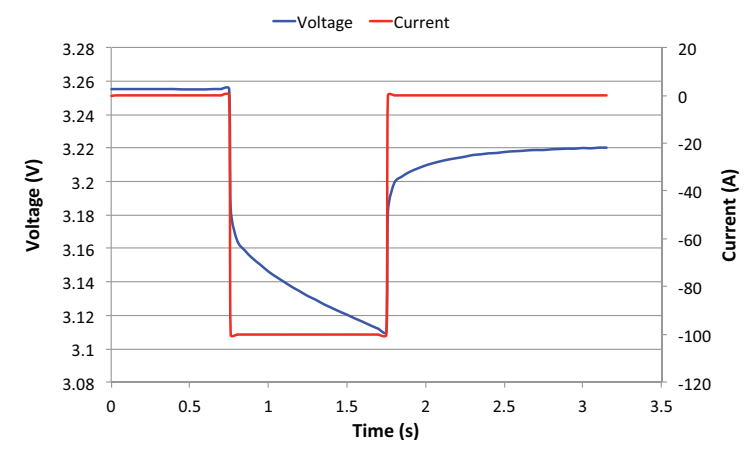

Figure 13: Voltage evolution of the LIC at room temperature during a pulse of $1 \mathrm{~s}$ at $25^{\circ} \mathrm{C}$

\section{Lithium-ion capacitor model}

As demonstrated in Table 1, LICs can be implemented in many applications. In order to make the use of this energy storage system possible, there is a need to have an accurate electrical model, which is able to predict the LIC performances during real operation of the system. Therefore, in this paper, the modified FreedomCar first order model has been used for this purpose as shown in Figure 14. In order to increase the model accuracy, the hysteresis has been taken into account by separating the charge and discharge ohmic resistances and polarization circuits.

The LIC model parameters have been estimated based on an advanced minimization technique at VUB. Therefore, the HPPC sequence has been conducted at different $\mathrm{SoC}$ (from $100 \%$ to $0 \%$ with steps of $5 \%)$, ambient temperatures $\left(60^{\circ} \mathrm{C}\right.$, $40^{\circ} \mathrm{C}, 25^{\circ} \mathrm{C}, 10^{\circ} \mathrm{C}, 0^{\circ} \mathrm{C}$ and $-10^{\circ} \mathrm{C}$ ) and current rates $(20 \mathrm{~A}, 40 \mathrm{~A}, 60 \mathrm{~A}, 80 \mathrm{~A}, 100 \mathrm{~A}, 120 \mathrm{~A}, 140 \mathrm{~A}$, $160 \mathrm{~A}, 180$ and 200A).

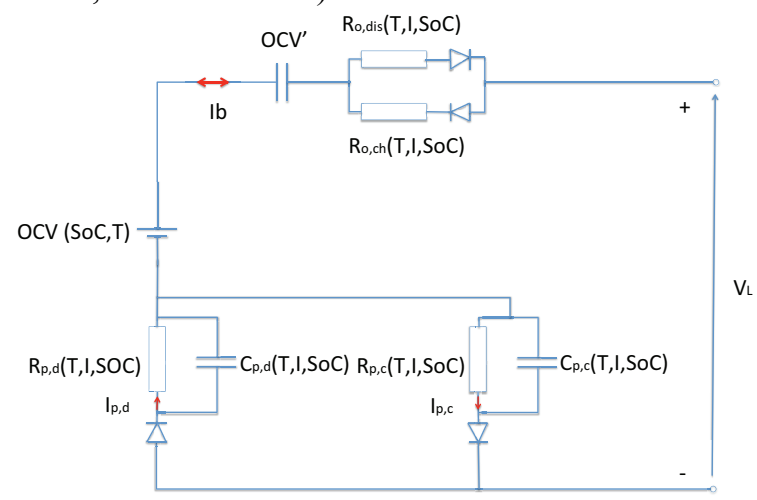

Figure 14: New electrical model for lithium-ion capacitor

In order to evaluate the accuracy of the new electrical model, two different load profiles have been selected. The first test is the discharge tests at $10 \mathrm{~A}$ and $25^{\circ} \mathrm{C}$ from $3.8 \mathrm{~V}$ till $2.2 \mathrm{~V}$ as shown in Figure 15. One can observe that the model is in good agreement with the experimental results. The maximum error percentage is around $0.25 \%$.

The second test is the dynamic discharge performance test as documented in the standard IEC 61982-2 [33]. In Figure 16, one can notice that the high performances of the model can be achieved when a dynamic load profile is applied. The error percentage between the model and the experimental result is about $1.5 \%$. The error percentage has been calculated based on equation (7).

Error $=\frac{\text { Voltage }_{\text {model }}-\text { Voltage }_{\text {experimental }}}{\text { Voltage }_{\text {model }}} \cdot 100 \%$
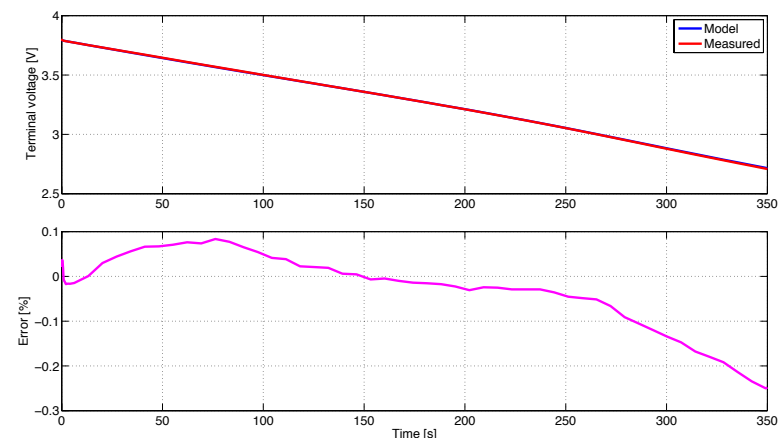

Figure 15: Comparison of the experimental and simulation based on constant $10 \mathrm{~A}$ discharging at $25^{\circ} \mathrm{C}$ 

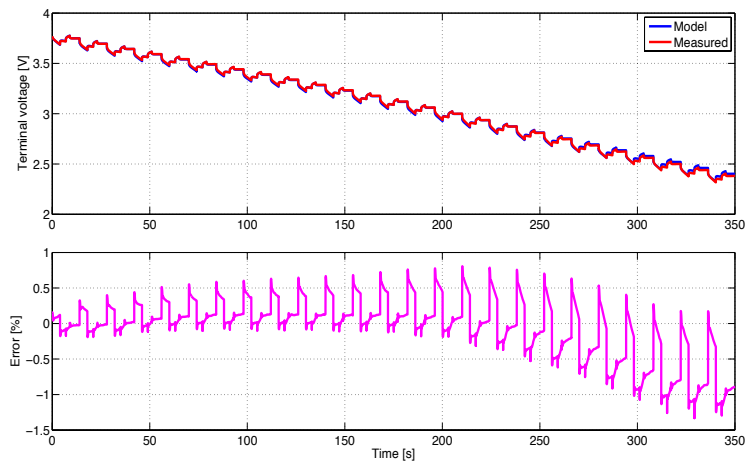

Figure 16: Comparison of the experimental and simulation based on DDP test at $25^{\circ} \mathrm{C}$

\section{Summary and conclusions}

In this paper, an extended analysis has been performed of the performances of lithium-ion

\section{References}

1. J. Van Mierlo, G. Maggetto, E. Van De Burgwal, R. Gense, Driving style and traffic measures influences vehicle emissions and fuel consumption, in Proceedings of the Institution of Mechanical Engineers, Part D, Journal of automobile engineering, Vol. 218, No. 1, 2003, PP: 43-50.

2. J. Van Mierlo, G. Maggetto, et al., Comparison of the environmental damage caused by vehicles with different alternative fuels and drive trains in a Brussels context, in: Proceedings on the Institution of Mechanical Engineers, Part D, Journal of automobile engineering, Vol. 217, No. 7, 2003, PP: 583-593.

3. J. Axsen, Burke, K. Kurani, Batteries for Plugin Hybrid Electric Vehicles (PHEVs): Goals and State of the Technology, May, 2008.

4. N. Omar, B. Verbrugge, P. Van den Bossche, J. Van Mierlo, Power and Life Enhancement of Battery-Electrical Double Layer Capacitor for Hybrid Electric and Charge-Depleting Plug-in Vehicle Applications, Journal of the Electrochimica, March, 2010.

5. P. Van den Bossche, F. Vergels, J. Van Mierlo, J. Matheys, W. Van Autenboer, SUBAT: an assessment of sustainable battery technology, Journal of Power Sources, Vol. 162, No. 2, 2006, PP: 913 - 919.

6. J. Axsen, K. S. Kurani, A. Burke, Are batteries ready for plug-in hybrid buyers, Journal of Transport Policy, Vol. 17, Feb. 2010, pp: 173180.

7. N. Omar, M. Daowd, B. Verbrugge, G. Mulder, P. Van den Bossche, J. Van Mierlo, M. Dhaens, S. Pauwels, F. Leemans, Assessment of Performance Characteristics of Lithium-Ion capacitors at different working conditions. Then, the characteristics of this technology have been investigated and we observed that lithium-ion capacitors could be categorized into high power lithium-ion batteries.

Furthermore, the experimental results showed that LIC could be an interesting candidate to replace EDLCs. Particularly, the combination of high power and high energy density can provide a better performance compared to the EDLCs in many applications. However, this technology offers advantages in terms of integration possibilities.

Finally, this paper proposes an enhanced electrical model, which can predict LIC behaviour accurately.

Batteries for PHEV Vehicles Applications Based on a Newly Test Methodology, The $25^{\text {th }}$ World Battery, Hybrid and Fuel Cell Electric Vehicle Symposium, November 5 9, 2010, Shenzhen, China.

8. N. Omar, M. Daowd, P. Van Den Bossche, O. Hegazy, G. Mulder, J. Smekens, Th. Coosemans, J. Van Mierlo, Rechargeable Energy Storage Systems for Plug-In Hybrid Electric Vehicles - Assessment of Electrical Characteristics, Journal of Energies, Vol. 5, pp: 2952-2988, 2012.

9. G. Mulder, N. Omar, S. Pauwels, F. Leemans, B. Verbrugge, W. De Nijs, P. Van den Bossche, D. Six, J. Van Mierlo, Comparison of commercial battery cells in relation to material properties, Electrochimica Acta, Vol. 87, pp: 473-488.

10. N. Omar, M. Daowd, G. Mulder, J.M. Timmermans, Th. Coosemans, P. Van den Bossche, J. Van Mierlo, S. Pauwels, Assessment of Performance of Lithium Iron Phosphate Oxide, Nickel Manganese Cobalt Oxide and Nickel Cobalt Aluminum Oxide Based cells for Using in Plug-in Battery Electric Vehicle Applications, IEEE Vehicle Power and Propulsion Conference (VPPC), Chicago, USA, 2011.

11. T. Ohzuk, R.J. Brodd, An overview of positiveelectrode materials for advanced lithium-ion batteries. Journal of Power Sources, 174:449456, 2007.

12. Belharouk, W. Lu, D. Vissers, Kh. Amine, Safety, characteristics of $\mathrm{Li}\left(\mathrm{Ni0} .{ }_{8} \mathrm{Co0.15 \textrm {Al } _ { 0 . 0 5 } ) \mathrm { O } _ { 2 }}\right.$ and $\mathrm{Li}\left(\mathrm{Ni}_{1 / 3} \mathrm{Co}_{1 / 3} \mathrm{Mn}_{1 / 3}\right) \mathrm{O}_{2}$, Journal of Power Sources, 8:329-335, 2006.

13. N. Omar, J. Van Mierlo, B. Verbrugge, P. Van Bossche, Power and life enhancement of battery-electrical double-layer capacitor for 
hybrid electric and charge-depleting plug-in vehicle applications, Electrochimica Acta, Vol. 55, pp: 7524-7531, 2010.

14. N. Omar, M. Daowd, O. Hegazy, P. Van den Bossche, Th. Coosemans, J. Van Mierlo, Electrical Double-Capacitors in Hybrid Topologies - Assessment and Evaluation of the Performances, Energies, Vol. 5, pp: 4533-4568, 2012.

15. Ch. Marumo, Design and performance of laminated lithium-ion capacitors, Advanced Capacitor World Summit 2008, San Diego, USA, 2008.

16. M. Risa, H. Yukinori, I. Masako, I. Koji, S. Daisuke, Development of High-Power LithiumIon Capacitor, General Paper.

17. G. G. Amatucci, F. Badway, A. Du Pasquier, T. Zheng, An Asymmetric Hybrid Non-asueous Energy Storage Cell, Journal of Electrochemistry Society, Vol. 148, pp: A930A939, 2001.

18. Y.G. Wang, L. Yu and Y.Y. Xia, Electrochemical capacitance performance of hybrid supercapacitors based on $\mathrm{Ni}(\mathrm{OH}) 2 /$ carbon nanutube comoistes and activated carbon, Journal of Electrochemistry Society, Vol. 153, pp: A743-A748, 2006.

19. Y.G. Wang, L. Y. Luo, C. Xiao and Y.Y. Xia, Hybrid a queous energy storage cells using activated carbon and lithium-ion intercalated compounds: II. Comparsion of LiMn2O4,

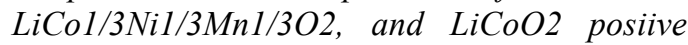
electrodes, Journal of Electrochemistry Society, Vol. 153, pp. A1425- A1431, 2006.

20. K. Karthikeyan, V. Aravindan, S.B. Lee, I.C. Jang, H.H. Lim, G.J. Park, M. Yoshio and Y.S. Lee, A novel asymmetric hybrid supercapacitor based on $\mathrm{Li}_{2} \mathrm{FeSiO}_{4}$ and activated carbon electrodes, Journal of Alloys Compounds, Vol. 504, pp. 224-227, 2010.

21. H. Culcu, H. Gualous, B. Verbrugge, P. Van den Bossche, J. Van Mierlo, Cell characterization of Lithium-ion capacitor with FreedomCAR and EIG method, EVS 24, Stavanger, Norway, 2009.

22. H. Gualous, G. Alcicek, Y. Diab, A. Hammar, P. Venet, K. Adams, M. Akiyama, C. Marumo, Lithium Ion capacitor characterization and modeling, ESSCAP'2008, Rome, Italy, 2008.
23. N. Omar, H. Gualous, M. Al Sakka, J. Van Mierlo, P. Van den Bossche, Electric and Thermal Characterization of Advanced Hybrid Li-Ion Capacitor Rechargeable Energy Storage System, Powergen 2013, Istanbul, Turkey, 2013.

24. N. Omar, M. Daowd, M. Al Sakka, Th. Coosemans, P. Van den Bossche, J. Van Mierlo, Assessment of Li-ion capacitor for using in BEV and HEV applications, Electrochimica Acta, Vol. 86, pp: 305-315, 2012.

25. D. Porcarelli, D. Brunelli, L. Benini, Characterization of Lithium-Ion Capacitors for low-Power energy neutral wireless sensor networks, $9^{\text {th }}$ International Conference on Networked Sensing Systems, Bologna, Italy, 2012.

26. S.M. Lambert, V. Pickert, J. Holden, X. He, W. $\mathrm{Li}$, Comparison of Supercapacitor and Lithium Ion Capacitor Technologies for Power Electronics Applications, 5th IET International Conference on Power Electronics, Machines and Drives (PEMD), Brighton, UK, 2012.

27. J. R. Miller, A. F. Burke, Electrochemical Capacitors: Challenges and Opportunities for Real World Applications, The Electrochemical Society Interface, 2008.

28. R. S. Sepe, A. Steyerl, S. P. Bastien, LithiumIon Supercapacitors for Pulsed Power Applications, Energy Conversion Congres and Exposition (ECCE), Phoenix, USA, 2011.

29. A. Hande, Internal battery temperature estimation using series battery resistance measurements during cold temperatures, Journal of Power Sources, vol. 158 (2006) 1039.

30. C. Forgez, D.V. Do, G. Friedrich, M. Morcrette, C. Delacourt, Thermal modeling of a cylindrical $\mathrm{LiFePO}_{4} /$ graphite lithium-ion battery, Journal of Power Sources 195 (2010) 2961.

31. IEC62576: Electric double-layer capacitors for use in hybrid electric vehicles - Test methods for electrical characteristics, 2009.

32. IEC 62660-1: Secondary lithium-ion cells for the propulsion of electric road vehicles - Part 1: Performance testing, 2010.

33. IEC 61982-2: Secondary batteries for the propulsion of electric road vehicles - Dynamic discharge performance test and dynamic endurance test, 2002. 
Authors

Dr. Eng. Omar Noshin
Vrije Universiteit Brussel
Email: noshomar@vub.ac.be
Noshin Omar was born in
Kurdistan, in 1982. He obtained the
M.S. degree in Electronics and
Mechanics from Erasmus University
College Brussels. He is currently
pursuing the PhD degree in the
department of Electrical
Engineering and Energy Technology
ETEC, at the Vrije Universitit
Brussel, Belgium. His research
interests include applications of
supercapacitors and batteries in
BEV's, HEV's and PHEV's. He is
also active in several international
standardization committees such as
IEC TC21/22.

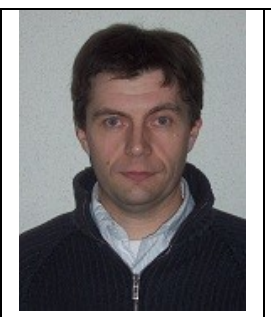

Jan Ronsmans

JSR Micro NV

Email: jan.ronsmans@jjsrmicro.be Jan Ronsmans was born in Leuven in 1972. He obtained a degree in Chemistry in 1995 and a degree in Industrial Electronics in 1999. After joining JSR Micro NV the year after, he worked for the company's semiconductor business for eight years. Since 2009, he is responsible for the Energy and Environment product portfolio, including JM Energy's lithium ion capacitor.

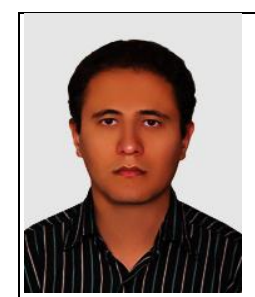

\section{Eng. Yousef Firouz}

Vrije Universitet Brussel

E-mail: yousef.firouz@vub.ac.be was born on 1983 in Iran. He received his M.Sc. in electrical engineering from a joint program between Leibniz University of Hannover-Germany and K.n.Toosi University of technology TehranIran in 2011. Currently he is doing his Ph.D in field of electric hybrid vehicles and energy storage in Vrije Universiteit Brussel.

His research interests are electrical and thermal modeling of batteries, $\mathrm{SoC}$ and $\mathrm{SoH}$ estimation, Power electronics, multilevel converters, reliability in power electronics and electrical machinery drive.

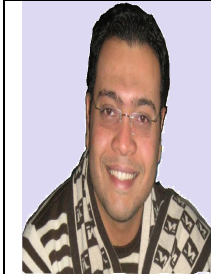

\section{Eng. Mohamed Abdel Monem}

Vrije Universiteit Brussel

Email:

mohamed.abdel.monem@vub.ac.be

Mohamed Abdel Monem was born in Cairo, Egypt, in 1982. He received the B.Sc. and M.Sc. degrees in Electrical Engineering from Helwan University, Cairo, Egypt, where he is currently working toward the Ph.D. degree in the Department of Electrical Engineering and Energy Technology (ETEC), Vrije Universiteit Brussel (VUB), Belgium. His current research interests include Second-Life Batteries, Battery Aging and Characterization, Systems Modelling, Parameter Estimation, Power Electronics, Renewable Energy, Control Systems and Battery Management System.

\begin{tabular}{|l|l|}
\hline & $\begin{array}{l}\text { Eng. Ahmadou Samba } \\
\text { University of Can Basse Normandie } \\
\text { Vrije Universiteit Brussel } \\
\text { Email: ahmadou.samba@vub.ac.be } \\
\text { Ahmadou Samba was born in } \\
\text { Senegal. He obtained the M.S. } \\
\text { degree in Energy and Mechanics } \\
\text { from Ecole des Mines of Nancy in } \\
\text { France. He is currently pursuing a } \\
\text { joint PhD degree in the department } \\
\text { of Electrical Engineering and } \\
\text { Energy Technology ETEC at the } \\
\text { Vrije Universiteit Brussel and also } \\
\text { in the department of Energetic } \\
\text { system at the University of Caen } \\
\text { Basse Normandie, France. His } \\
\text { research interests include } \\
\text { applications of supercapacitors and } \\
\text { batteries in term of electrical } \\
\text { characterization and thermal } \\
\text { management. }\end{array}$ \\
\hline
\end{tabular}

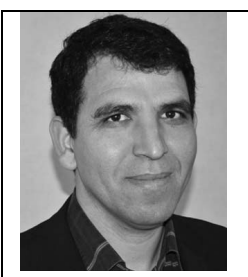

\section{Prof. Dr. Ir. Hamid Gualous}

University of Can Basse Normandie Email: hamid.gualous@unicaen.fr Hamid Gualous received his Ph.D. degree in electronic from the University Paris XI Orsay, France, in 1994. From 1996 to 2009 he was an Associate Professor at the University of Franche-Comte, FEMTO-ST Laboratory, France. Since 2009, he is Full Professor at the University of Caen Basse Normandie, France. His main research activities are concerning energy storagedevices 


\begin{tabular}{|l|lr|}
\hline & $\begin{array}{l}\text { supercapacitors and batteries), } \\
\text { hybrid power sources (fuel cell- } \\
\text { supercapacitor battery) and energy } \\
\text { management for } \\
\text { applications. }\end{array}$ \\
\hline
\end{tabular}

Dr.ir. Omar Hegazy
Vrije Universiteit Brussel
Email: omar.hegazy@vub.ac.be
Omar Hegazy (M'09) was born in
Cairo, Egypt, in 1978. He received
the B.Sc. (Hons.) and M.Sc. degrees
in electrical engineering from
Helwan University, Cairo and the
Ph.D. degree (with the greatest
distinction) from the Department of
Electrical Machines and Power
Engineering (ETEC), Vrije
Universiteit Brussel (VUB),
Brussels, Belgium, in July 2012. He
is currently a Postdoctoral Fellow at
ETEC and MOBI team at VUB. He
is the author of more than 40
scientific publications. He is a
member of IEC standards for
wireless power transfer systems.
Currently, he is involved in different
FP7 projects (such as Safedrive and
Unplugged). His current research
interests include power electronics,
drive systems, electric vehicles,
(plug-in) hybrid electric vehicles,
power management strategies,
battery management systems,
renewable energy, control systems,
and optimization techniques.

\begin{tabular}{|l|l|}
\hline & $\begin{array}{l}\text { Prof. Dr. ir. Thierry Coosemans } \\
\text { Vrije Universiteit Brussel } \\
\text { Email:thierry.coosemans@vub.ac.be } \\
\text { Thierry Coosemans obtained his } \\
\text { PhD in Engineering Sciences from } \\
\text { Ghent University in 2006. After } \\
\text { several years in the industry, he now } \\
\text { became a member of the ETEC } \\
\text { research team on transport } \\
\text { technology at the VUB, where he } \\
\text { works as a scientific project } \\
\text { manager. }\end{array}$ \\
\hline
\end{tabular}

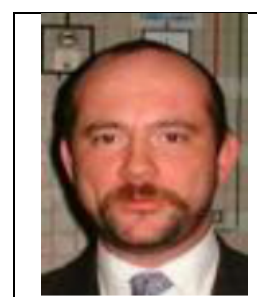

Prof. Dr. ir. Van den Bossche Peter

Vrije Universiteit Brussel

Email:pvdbos@vub.ac.be

Peter Van den Bossche graduated as civil mechanical-electrotechnical engineer from the Vrije Universiteit Brussel and defended his $\mathrm{PhD}$ at the same institution with the thesis "The Electric Vehicle: raising the standards". He is currently lecturer

\begin{tabular}{|l|l|}
\hline at the engineering faculties of the \\
Vrije Universiteit Brussel, and in \\
charge of co-ordinating research and \\
demonstration projects for electric \\
vehicles in collaboration with the \\
international associations CITELEC \\
and AVERE. His main research \\
interest is electric vehicle \\
standardization, in which quality he \\
is involved in international \\
standards committees such as IEC \\
TC69, of which he is Secretary, and \\
ISO TC22 SC21.
\end{tabular}

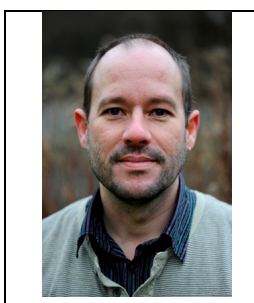

Prof. Dr. ir. Joeri Van Mierlo

Vrije Universiteit Brussel

Email: jvmierlo@vub.ac.be

Joeri Van Mierlo obtained his

Ph.D. in electromechanical Engineering Sciences from the Vrije Universiteit Brussel in 2000. He is now a full-time professor at this university, where he leads the MOBI - Mobility and automotive technology research centre (http://mobi.vub.ac.be). Currently his activities are devoted to the development of hybrid propulsion (power converters, energy storage, energy management, etc.) systems as well as to the environmental comparison of vehicles with different kind of drive trains and fuels (LCA, WTW). He is the author of more than 200 scientific publications. Prof. Van Mierlo chairs the EPE chapter "Hybrid and electric vehicles" (www.epeassociation.org); he is the secretary of the board of the Belgian section of AVERE (ASBE) (www.asbe.be) and is Vice-president of AVERE (www.avere.org). $\mathrm{He}$ is editor in chief of the World Electric Vehicle Journal Volume 3 and co-editor of the Journal of Asian Electric Vehicles. He is an active member of EARPA - the European Automotive Research Partner Association. Furthermore he is member of Flanders Drive and of VSWB Flemish Cooperative on hydrogen and Fuels Cells. Prof. Van Mierlo was Chairman of the International Program Committee of the International Electric, hybrid and fuel cell symposium (EVS24). 